\title{
Relationship Between Botulinum Toxin, Spasticity, and Pain: a Survey of Patient Perception
}

\author{
Adil Shaikh, Chetan P Phadke, Farooq Ismail, Chris Boulias
}

\begin{abstract}
Objective: To assess the prevalence of pain in adults with spasticity and to assess the association between the subjective experience of pain and spasticity. Design: Cross-sectional study. Setting: outpatient spasticity management clinic of a rehabilitation centre. Patients: Patients with upper motor neuron lesions and spasticity $(\mathrm{n}=131)$ were recruited. Methods: We assessed pain intensity and location, relationship between spasticity and pain perception, and perception of pain relief from botulinum toxin type-A (BoNTA) injections. Main outcome measures: Pain perception rated on a 10-point numerical rating scale and pain quality. Results: $65 \%$ of the patients with spasticity reported presence of pain and $60 \%$ described it as an aching pain. More patients reported pain with movement (34\%) compared to rest $(21 \%)$. There was a statistically poor correlation between the severity of pain and spasticity $(\mathrm{r}=0.16$; $\mathrm{p}>0.05)$. Most patients $(80 \%)$ believed that their pain was related to spasticity and $62 \%$ reported that BoNTA injections decreased their pain. Conclusions: The high incidence of pain noted within our sample suggests that physicians may have to consider pain management as part of spasticity treatment. Participants reported that their pain was related to their spasticity, and that it decreased after BoNTA treatment. Further study is needed to explore the relationships between objective measures of spasticity and pain.
\end{abstract}

RÉSUMÉ: Relation entre la toxine botulique, la spasticité et la douleur : une enquête sur la perception des patients. Objectif: Le but de l'étude était de déterminer la prévalence de la douleur chez des adultes souffrant de spasticité et d'étudier l'association entre l'expérience subjective de la douleur et la spasticité. Devis de l'étude: Il s'agit d'une étude transversale. Contexte: Cette étude a été réalisée auprès de patients fréquentant une clinique dédiée au traitement de la spasticité dans un centre de réadaptation. Patients: Des patients atteints de lésions du neurone moteur supérieur et de spasticité ont été recrutés $(\mathrm{n}=131)$. Méthode: Nous avons évalué l'intensité et la localisation de la douleur, la relation entre la spasticité et la perception de la douleur ainsi que la perception du soulagement de la douleur suite à des injections de toxine botulique de type A (BoNTA). Principaux critères d'évaluation: Les critères utilisés étaient la perception de la douleur évaluée sur une échelle numérique de 10 points et la qualité de la douleur. Résultats: Soixante-cinq pour cent des patients présentant de la spasticité ont rapporté la présence de douleur et $60 \%$ l'ont décrite comme une douleur sourde. Plus de patients ont rapporté de la douleur au mouvement (34\%) qu'au repos (21\%). La corrélation entre la sévérité de la douleur et la spasticité était faible au point de vue statistique (r =0,16; $\mathrm{p}>0,05)$. La plupart des patients $(80 \%)$ croyaient que leur douleur était reliée à la spasticité et $62 \%$ rapportaient que les injections de BoNTA diminuaient la douleur. Conclusions: L'incidence élevée de douleur notée dans notre échantillon de patients suggère que les médecins devraient considérer la gestion de la douleur comme faisant partie du traitement de la spasticité. Les participants ont rapporté que leur douleur était reliée à la spasticité et qu'elle diminuait après le traitement par la BoNTA. Des études supplémentaires seront nécessaire afin d'explorer la relation entre des mesures objectives de la spasticité et la douleur.

Keywords: botulinum toxin, cerebral palsy, muscle spasticity, multiple sclerosis, pain, spinal cord injury, stroke

Spasticity is a motor disorder characterized by a velocitydependent increase in tonic stretch reflexes, with exaggerated tendon jerks, resulting from hyper-excitability of the stretch reflex as one component of the upper motor neuron (UMN) syndrome. ${ }^{1}$ It occurs in many neurological conditions, including multiple sclerosis (MS), cerebral palsy (CP), spinal cord injury (SCI), stroke, and traumatic brain injury (TBI). ${ }^{2}$ The treatment options can vary but can involve physical and occupational therapy; pharmacological interventions such as oral medications, intrathecal therapies and intramuscular injections; and surgical interventions. ${ }^{3}$ Currently, amongst the pharmacological interventions, botulinum toxin intramuscular injections are widely used for focal spasticity (present in discrete locations). ${ }^{3}$
Botulinum toxin acts at the neuromuscular junction to block neural transmission, decreasing muscle activation and thus decreasing dynamic tone. ${ }^{3}$

Patients with spasticity can also experience pain ${ }^{4}$ and in our clinical practice, patients with spasticity often have pain and

From the Spasticity Research Program (AS, CPP, FI, CB), Department of Physical Therapy (CPP); Division of Physical Medicine and Rehabilitation (AS, FI, CB), Faculty of Medicine, University of Toronto; Faculty of Health (CPP), York University, Toronto, Ontario, Canada.

Received May 26, 2015. Final Revisions Submitted August 6, 2015.

Correspondence to: Chetan P. Phadke, Spasticity Research Program, West Park Healthcare Centre, Toronto, ON, Canada M6M 2J5. Email: chetan.phadke@westpark.org 
spasms (a sudden involuntary muscle contraction). Pain prevalence ranges from $30-60 \%$ in patients with $\mathrm{MS}^{5}$ and $\mathrm{SCI}^{6}$ about $15 \%$ in acute ${ }^{7}$ stroke (less than year post-stroke, at least partially attributed to spasticity ${ }^{8}$ ), and increases to about $39 \%$ in patients with chronic stroke ${ }^{9}$ (more than two years). In the patients with pain, $41 \%$ had spasticity if the pain was stroke related and only $5 \%$ had spasticity if the pain was non-stroke related. ${ }^{10}$ Several potential causes of pain such as spasticity, shoulder-hand syndrome, and central post-stroke pain have been identified ${ }^{10}$; however, the relationship between spasticity and pain has not been assessed in other non-stroke patient populations. Thus, it is important to know if there is a bidirectional association between pain and spasticity.

There is conflicting evidence on whether botulinum toxin type A (BoNTA) injections can help decrease pain. Meta-analysis of the effect of botulinum neurotoxin on low back pain demonstrated reduced pain at three and eight weeks post-BoNTA injection. ${ }^{11}$ In women with pelvic floor muscle overactivity and a two-year history of pelvic pain, BoNTA injections have resulted in a significant reduction in dyspareunia. ${ }^{12}$ Botulinum toxin type A has also been shown to be an effective prophylactic in patients with chronic migraine and primary stabbing headaches. ${ }^{13,14}$ However, some studies have shown no difference in pain after four weeks. ${ }^{15,16}$ Thus, although BoNTA is known to effectively decrease spasticity, ${ }^{3}$ it is not clear if BoNTA also simultaneously decreases pain as a result of reduction in spasticity.

For clinicians that manage patients with spasticity, further evidence, especially in relation to patient perceptions, is required to clarify the full benefit of intramuscular botulinum toxin injections. Our overall aim was to assess the relationship between spasticity and pain. To help address this, our cross-sectional study examined 1) the prevalence of pain in patients with spasticity; 2) the type of pain exhibited; 3) patient perception of the association between pain and spasticity and spasm; and 4) perception of change in pain in relation to botulinum injections. This, along with further analysis of the type of pain experienced, may pave the way towards a paradigm shift of how treatment of spasticity is viewed.

\section{METHODS \\ Participants}

One hundred and thirty one consecutive patients were recruited from a Spasticity Clinic based on the following inclusion criteria: 1) currently receiving ongoing intra-muscular BoNTA injections or BoNTA naïve (scheduled to receive injections on the day of testing), 2) above the age of eighteen, and 3) objective evidence of spasticity (based on modified Ashworth Scale - MAS score of at least 1). Patients were excluded from the study if they could not communicate with the clinic staff or caregivers; or had cognitive deficits (inability to answer simple yes or no questions as determined by the treating physicians) that would designate them unable to answer the questions in the questionnaire accurately.

All participants provided written informed consent approved by the hospital Research Ethics Board and procedures followed were in accordance with the Helsinki Declaration of 1975, as revised in 1983. After the consent form was signed, the questionnaire was completed while the patients were waiting to be seen by their physician in the clinic.

\section{Outcome measures}

We used a WILDA (Words, intensity, location, duration, aggravating/alleviating factors) approach to assess pain in our participants ${ }^{16}$ (see the online supplementary Appendix 1 for the pain questionnaire used in this study). Verbally administered Numerical Rating Scale (NRS), a psychometric scale with scores ranging from 0-10 (' 0 ' indicates no pain and ' 10 ' indicates unbearable pain), is a validated ${ }^{18}$ (commonly used, ${ }^{19}$ standardized approach to measuring pain ${ }^{20}$ and was incorporated in the questionnaire to assess pain intensity. Patients verbally specified their pain severity by indicating a number between two end-points ( 0 and 10). The questionnaire assessed the presence of pain with words describing pain, pain intensity, location of pain (using tick boxes), medication use, factors aggravating/alleviating pain (subjective relationship of pain to movement of the involved limb), effect of spasticity on pain perception, and perception of pain relief from botulinum toxin injections. The items included in the pain questionnaire were based on previous research articles that described different types of pain. ${ }^{17,21,22}$ After the questionnaire was completed, spasticity was assessed by two experienced (more than five years' experience assessing patients with spasticity as a result of common UMN lesions) physical and occupational therapists (using MAS). The physical therapist only assessed lower limb spasticity and the occupational therapist only assessed upper limb spasticity. To get a MAS score, the tested joint is briskly moved and a rating (0-4) is assigned based on the nature and quality of resistance to passive movement experienced by the rater. Scoring system -0 : no increase in resistance, 1 : slight catch or increase in muscle tone near the end of movement, 1+: slight catch with minimal increase in resistance through the remaining range of motion, 2: more marked increase in muscle tone through most of the range of motion, 3: considerable increase in muscle tone with difficulty moving the joint, and 4: affected part rigid (contracture). ${ }^{23}$ The MAS has moderate interrater reliability $^{24}$ and is a commonly used clinically feasible test of spasticity severity that has been associated with sensitivity of the stretch reflex receptors. ${ }^{25}$ In cases where pain was reported in more than one location, the MAS score in the location with the most pain was documented. The data was collected from the patients prior to receiving intramuscular BoNTA injections.

\section{Data analysis}

We used an online analysis software (Sampsize 0.6.0), to determine the precision level (with a $95 \%$ confidence interval) of the observed spasticity prevalence. Descriptive analyses were performed and Pearson's correlation coefficient was calculated to measure the strength of linear dependence between subjective pain descriptors and MAS spasticity severity using SPSS software version 20.0 (IBM Corp., New York, NY, USA). Graphs were created using Microsoft Excel add-on (XL Toolbox (C) 2008-2011 Daniel Kraus, Würzburg, Germany).

\section{RESULTS}

Of the 131 patients with spasticity enrolled in the study, $47 \%$ had a primary diagnosis of stroke. Other frequent etiologies included MS, CP, SCI and TBI at rates of $19 \%, 12 \%, 9 \%$ and $8 \%$, respectively. Less common causes of spasticity in our sample included Behcet's disease, encephalitis, hereditary spastic 


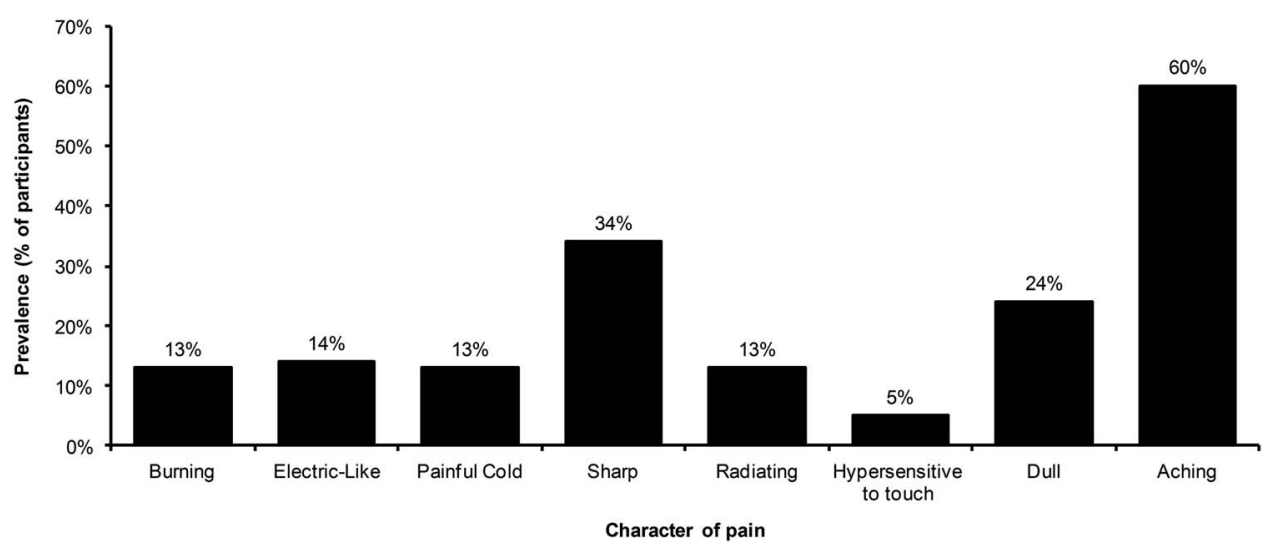

Figure 1: Patient reported pain type

paraparesis, and hydrocephalus - and each accounted for less than $2 \%$ of the patients. The ages of the patients in the study ranged from 20 to 90 years - mean 57.28 years (standard deviation 16.79 years; mode 78 years). Of the 131 participants, 66 were males and 65 females. A majority of our patients typically receive BoNTA injections at an interval of three to six months. Of all participants, $20 \%$ self-reported some degree of memory deficit. Only three patients reported a previous history of pain that occurred prior to the onset of neurological disorder (not relevant to patients with cerebral palsy).

\section{Prevalence}

Eighty five out of 131 patients with spasticity reported pain and prevalence was $65 \%$ (ranging from $56.5 \%$ to $73.5 \%$ based on $8.5 \%$ precision level). Patients with $\mathrm{CP}$ had the highest prevalence of pain $(87 \%)$. Patients with MS, SCI, stroke, and TBI had prevalence of pain similar to the total group average in the rates of $64 \%, 67 \%, 61 \%$ and $64 \%$, respectively. Median MAS score in our patient group was 2 and $59 \%$ of patients were on analgesics ranging from over the counter drugs containing acetaminophen to stronger prescription medications containing oxycodone hydrochloride and acetaminophen. A small percentage of patients was on anti-depressants and $31 \%$ of patients were also receiving oral anti-spasticity medications.

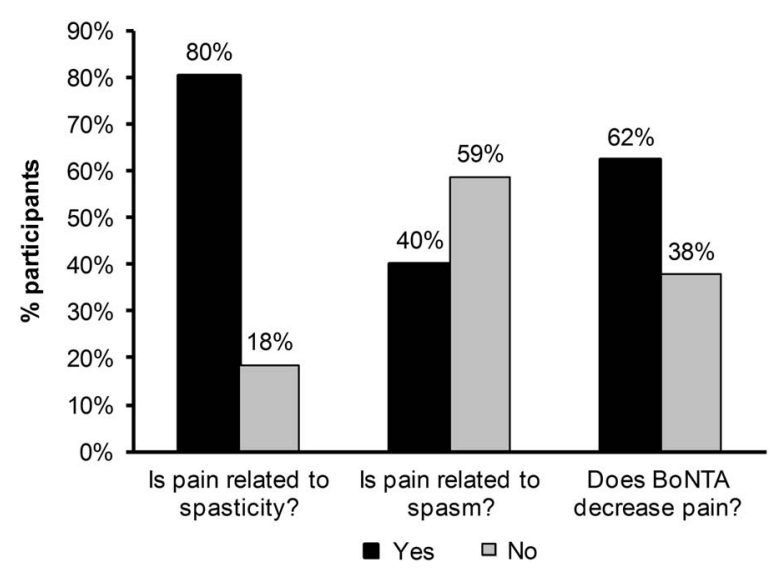

Figure 2: Relationship between pain, spasticity, and botulinum toxin

\section{Character of pain}

Although a few patients described their pain with more than one character, the most common description of the character of pain was aching $(60 \%)$, sharp (34\%), or dull $(24 \%)$ as depicted in Figure 1 . Less than $14 \%$ of the patients described their pain in ways consistent with a neuropathic nature (such as burning, electric-like, or painfully cold). ${ }^{17}$

Although $45 \%$ of participants stated that the pain occurred both during movement of the spastic limb and during rest, the pain was reported to occur more often during movement compared to at rest (34\% vs. $21 \%)$.

Pearson correlation coefficient between pain severity score (NRS) and severity of spasticity (MAS) was non-significant $(\mathrm{r}=0.16 ; \mathrm{p}>0.05)$.

The majority of the patients $(80 \%)$ reported that their pain was related to self-perception of spasticity. In contrast, 59\% of patients did not think that their pain was related to spasms. The majority of patients (all but eight patients) had previously received intramuscular BoNTA for the treatment of spasticity; $62 \%$ of this group reported a decrease in pain, while $38 \%$ reported no change in pain status (Figure 2).

\section{DISCUSSION}

Previous multicenter studies have shown the prevalence of pain in the CP population to be $75-80 \%{ }^{26,27}$ which is similar to the prevalence of $87 \%$ in $\mathrm{CP}$ patients with spasticity found in the current study. Likewise, our data in patients with spasticity concurs with previous studies that reported prevalence of pain in stroke to be $19-75 \%,{ }^{26-28} 53 \%$ in $\mathrm{MS},{ }^{29} 64.9 \%$ in $\mathrm{SCI}^{30}$ and $70 \%$ in brain injured patients. ${ }^{31}$ The Cochrane Collaboration Systematic Review $^{32}$ reported a decrease in shoulder pain after injection of BoNTA; but in contrast, our study provides data on the prevalence of pain at any site in the body (not limited to shoulder pain) in patients experiencing spasticity due to various etiologies. Thus, our study results provide unique data to help understand patient perception of pain within the context of the experience of spasticity.

The pain descriptors typically associated with neuropathic pain $^{33}$ such as 'electric like', 'burning', and 'cold' were reported by up to $14 \%$ of our sample. In contrast, the pain descriptor 'aching' typically associated with nociceptive pain ${ }^{34}$ was reported by $60 \%$ of our sample. This finding suggests that the origin of the 
pain may be abnormality in the muscle (or connective tissue). Our patients also reported higher rates of pain with movement of the limb compared to rest suggesting that the pain may have been nociceptive. It should be noted though that the patient reports of pain perception are not enough to discriminate between causes of pain. Our patients reported an important distinction between perception of pain in relation to spasticity and spasms. Spasms are typically of brief duration ${ }^{35}$ compared to the experience of spasticity, which can lead to patients experiencing muscle stiffness. ${ }^{36}$ It is possible that the shorter duration of spasm did not significantly add to the experience of pain; whereas, the longer lasting effects of spasticity may have resulted in nociceptive experience of pain.

Pain perception was not related to MAS severity in our study. One possible explanation for the low correlation is that the location where the spasticity was documented was not always the same as the location of pain. We chose to assess the pain-spasticity relationship in the way we did because it is difficult and unrealistic to assess pain rating in every spastic muscle on a regular visit. Furthermore, $59 \%$ of the study participants were on analgesics that could confound the severity of pain.

About two thirds of the patients that experienced pain in our study and had previously received intramuscular BoNTA injections reported a decrease in pain as a result of BoNTA. Although BoNTA for treatment of pain has been documented in other neurological conditions, ${ }^{37}$ clear evidence is not available for pain relief with spasticity. Contradictory evidence exists in the form of no difference between BoNTA and placebo $^{16}$ and BoNTA producing greater pain relief compared to the conventional intraarticular steroid injections for post-stroke shoulder pain. ${ }^{38}$

The analgesic effects of BoNTA have also been reported in conditions not associated with spasticity. ${ }^{38}$ leading to the possibility that BoNTA may have a direct pain relieving effect. The exact underlying mechanism of this phenomenon is still uncertain but animal models show that BoNTA inhibits pain modulating neurotransmitter release from synaptosomes. ${ }^{39}$ In addition, botulinum toxin has been shown to enhance analgesia.

\section{Study limitations}

An important limitation in our study was that the measurement of pain was not done specifically in the muscle groups with spasticity and our questionnaire has not been validated. Moreover, looking at our results, pain was found to be subjectively associated with spasticity, but a direct relationship cannot be inferred through this cross-sectional observational study. Only patients scheduled to receive botulinum toxin injections were included in this study presenting a selection bias. Often the physicians were not blinded to the patient's MAS and the patient themselves may feel the need to impress the physicians by stating that they have improved after administration of BoNTA. Also, we were unable to take into account other oral analgesics and muscle relaxants that patients may have been taking. The self-reported memory deficit in $20 \%$ of our sample, together with the three to six month time elapsed since previous injection, may have introduced a recollection bias in this study. The survey did not directly address whether or not patient satisfaction with spasticity treatment is related to improvement in pain. It would be of value to know the relative influence of pain relief compared to improvements in function and spasticity on patient satisfaction.

\section{Conclusion}

The majority of patients with spasticity originating from a variety of CNS-related disorders experienced pain to varying degrees. This pain may be nociceptive in origin and related to movement. Although the severity of spasticity did not correlate statistically with the amount of pain experienced, subjectively the pain was reported to be related to spasticity. The patients perceived a decrease in their pain as a result of BoNTA injection. Based on the high (65\%) prevalence of pain in our patients experiencing spasticity, it appears that physicians may have to consider treatment of pain as part of spasticity management. Further studies are needed to explore the mechanisms underpinning pain relief from BoNTA injections for limb spasticity.

\section{Disclosures}

Adil Shaikh does not have anything to disclose. Chetan Phadke has the following disclosure: Merz/Allergan - Independent investigator, Grant/Honoraria. Farooq Ismail has the following disclosure: Merz/Allergan - Independent investigator, Grant/ Honoraria. Chris Boulias has the following disclosure: Merz/ Allergan - Independent investigator, Grant/Honoraria

\section{SUPPLEMENTARY MATERIAL}

To view supplementary material for this article, please visit http://dx.doi.org/10.1017/cjn.2015.321.

\section{REFERENCES}

1. Lance J. Symposium synopsis. In: Feldman R, Young R, Koella W, editors. Spasticity disordered motor control. Chicago: Year Book Medical Publishers; 1980:485-94.

2. Weiss E, David L. Spasticity. Therapeutic Uses of Botulinum Toxin: Humana Press; 2007:7-18.

3. Graham LA. Management of spasticity revisited. Age Ageing. 2013;42:435-41.

4. Wissel J, Manack A, M B. Toward an epidemiology of poststroke spasticity. Neurolog. 2013;15(Suppl 2):S13-9.

5. Martinelli Boneschi F, Colombo B, Annovazzi P, Martinelli V, Bernasconi L, Solaro C, et al. Lifetime and actual prevalence of pain and headache in multiple sclerosis. Mult Scler. 2008;14:514-21.

6. Sjölund B. Pain and rehabilitation after spinal cord injury: the case of. Brain Res Brain Res Rev. 2002;40:250-6.

7. Wisse 1J, Schelosky L, Scott J, Christe W, Faiss J, Mueller J. Early development of spasticity following stroke: a prospective, observational trial. J Neurol. 2010;257:1067-72.

8. Hansen A, Klit H, Brix Finnerup N, Anderson G, Staehelin JT. Spasticity, Spasms and Chronic Pain Following Stroke: A Prospective Study. Eur J Pain. 2009;13:S55-285.

9. Klit H, Finnerup N, Overvad K, Andersen G, Jensen T. Pain following stroke: a population-based follow-up study. PLoS One. 2011;6:e27607.

10. Lundström E, Smits A, Terént A, Borg J. Risk factors for strokerelated pain 1 year after first-ever stroke. Eur $\mathrm{J}$ Neurol. 2009;16:188-93.

11. Sakamoto T. Molecular mechanism of botlinum toxin therapy for spasticity. Rinsho Shinkeigaku. 2012;52:1270-1.

12. Nesbitt-Hawes E, Won H, Jarvis S, Lyons S, Vancaillie T, Abbott J. Improvement in pelvic pain with botulinum toxin type A - Single vs. repeat injections. Toxicon. 2012;6:83-7.

13. Ashkenazi A, Blumenfeld A. OnabotulinumtoxinA for the treatment of headache. Headache. 2013;53(Suppl 2):54-61.

14. Piovesan EJ, Teive HG, Kowacs PA, Silva LL, Werneck LC. Botulinum neurotoxin type-A for primary stabbing headache: an open study. Arq Neuropsiquiatr. 2010;68:212-5. 
15. Hyman N, Barnes M, Bhakta B, Cozens A, Bakheit M, Kreczy-Kleedorfer B, et al. Botulinum toxin (Dysportt) treatment of hip adductor spasticity in multiple sclerosis: a prospective, randomised, double blind, placebo controlled, dose ranging study. J Neurol Neurosurg Psychiatry. 2000;68:707-12.

16. Marciniak CM, Harvey RL, Gagnon CM, Duraski SA, Denby FA, McCarty S, et al. Does botulinum toxin type A decrease pain and lessen disability in hemiplegic survivors of stroke with shoulder pain and spasticity?: a randomized, double-blind, placebocontrolled trial. Am J Phys Med Rehabil. 2012;91:1007-19.

17. Fink R. Pain assessment: the cornerstone to optimal pain management. Proc (Bayl Univ Med Cent). 2000;13:236-9.

18. Bijur PE, Latimer CT, Gallagher EJ. Validation of a verbally administered numerical rating scale of acute pain for use in the emergency department. Acad Emerg Med. 2003;10:390-2.

19. Novak CB, Katz J. Neuropathic pain in patients with upper-extremity nerve injury. Physiother Can. 2010;62:190-201.

20. Dalton JA, McNaull F. A call for standardizing the clinical rating of pain intensity using a 0 to 10 rating scale. Cancer Nurs. 1998;21:46-9.

21. Baron R, Binder A, Wasner G. Neuropathic pain: diagnosis, pathophysiological mechanisms, and treatment. Lancet Neurol. 2010;9:807-19.

22. Bennett MI, Attal N, Backonja MM, Baron R, Bouhassira D, Freynhagen R, et al. Using screening tools to identify neuropathic pain. Pain. 2007;127:199-203.

23. Blackburn M, van Vliet P, Mockett SP. Reliability of measurements obtained with the modified Ashworth scale in the lower extremities of people with stroke. Phys Ther. 2002;82:25-34.

24. Fleuren JF, Voerman GE, Erren-Wolters CV, Snoek GJ, Rietman JS, Hermens HJ, et al. Stop using the Ashworth Scale for the assessment of spasticity. J Neurol Neurosurg Psychiatry. 2010;81:46-52.

25. Phadke C, On A, Kirazli Y, Ismail F, Boulias C. Intrafusal effects of botulinum toxin injections for spasticity: revisiting a previous paper Neuroscience Letters. Neurosci Lett. 2013; Accepted manuscript in press.

26. Parkinson KN, Dickinson HO, Arnaud C, Lyons A, Colver A. Pain in young people aged 13 to 17 years with cerebral palsy: cross-sectional, multicentre European study. Arch Dis Child. 2013 Jun;98:434-40.

27. Van Der Slot WM, Nieuwenhuijsen C, Van Den Berg-Emons RJ, Bergen MP, Hilberink SR, Stam HJ, et al. Chronic pain, fatigue, and depressive symptoms in adults with spastic bilateral cerebral palsy. Dev Med Child Neurol. 2012;54:836-42.

28. Jönsson AC, Lindgren I, Hallström B, Norrving B, Lindgren A. Prevalence and intensity of pain after stroke: a population based study focusing on patients' perspectives. J Neurol Neurosurg Psychiatry. 2006;77:590-5.

29. Archibald CJ, McGrath PJ, Ritvo PG, Fisk JD, Bhan V, Maxner CE, et al. Pain prevalence, severity and impact in a clinic sample of multiple sclerosis patients. Pain. 1994;58:89-93.

30. Modirian E, Pirouzi P, Soroush M, Karbalaei-Esmaeili S, Shojaei H, Zamani H. Chronic pain after spinal cord injury: results of a longterm study. Pain Med. 2010;11:1037-43.

31. Taylor BC, Hagel EM, Carlson KF, Cifu DX, Cutting A, Bidelspach DE, et al. Prevalence and costs of co-occurring traumatic brain injury with and without psychiatric disturbance and pain among Afghanistan and Iraq War Veteran V.A. users. Med Care. 2012;50:342-6.

32. Singh JA, Fitzgerald PM. Botulinum toxin for shoulder pain. Cochrane Database Syst Rev. 2010(9):CD008271.

33. Boureau F, Doubrère JF, Luu M. Study of verbal description in neuropathic pain. Pain. 1990 Aug;42:145-52.

34. Marchettini P, Lacerenza M, Mauri E, Marangoni C. Painful peripheral neuropathies. Curr Neuropharmacol. 2006;4: 175-81.

35. Jasmin L. Hand or foot spasms. US National Library of Medicine; Available from: http://www.nlm.nih.gov/medlineplus/ency/ article/003194.htm.

36. UK MSo. Muscle spasms and stiffness. MS Essentials For people living with MS 19 [serial on the Internet]. 2011: Available from: http://www.mssociety.org.uk/ms-resources/muscle-spasms-andstiffness-ms-essentials-19.

37. Jabbari B, Machado D. Treatment of refractory pain with botulinum toxins-an evidence-based review. Pain Med. 2011;12:1594-606.

38. Lim JY, Koh JH, Paik NJ. Intramuscular botulinum toxin-A reduces hemiplegic shoulder pain: a randomized, double-blind, comparative study versus intraarticular triamcinolone acetonide. Stroke. 2008;39:126-31.

39. McMahon HT, Foran P, Dolly JO, Verhage M, Wiegant VM, Nicholls DG. Tetanus toxin and botulinum toxins type A and B inhibit glutamate, gamma-aminobutyric acid, aspartate, and met-enkephalin release from synaptosomes. Clues to the locus of action. J Biol Chem. 1992 Oct;267:21338-43. 